\title{
Wild-type huntingtin ameliorates striatal neuronal atrophy but does not prevent other abnormalities in the YACI 28 mouse model of Huntington disease
}

\author{
Jeremy M Van Raamsdonk, Jacqueline Pearson, Zoe Murphy, \\ Michael R Hayden* and Blair R Leavitt
}

\author{
Address: Department of Medical Genetics and Centre for Molecular Medicine and Therapeutics, Child and Family Research Institute, University \\ of British Columbia, Vancouver, V5Z 4H4, BC, Canada \\ Email: Jeremy M Van Raamsdonk - jeremy@cmmt.ubc.ca; Jacqueline Pearson - jacqui@cmmt.ubc.ca; Zoe Murphy - zmurphy@cmmt.ubc.ca; \\ Michael R Hayden* - mrh@cmmt.ubc.ca; Blair R Leavitt - bleavitt@cmmt.ubc.ca \\ * Corresponding author
}

Published: 05 December 2006

BMC Neuroscience 2006, 7:80 doi:10.1 I86/147/-2202-7-80

This article is available from: http://www.biomedcentral.com//47/-2202/7/80

(C) 2006 Van Raamsdonk et al; licensee BioMed Central Ltd.

This is an Open Access article distributed under the terms of the Creative Commons Attribution License (http://creativecommons.org/licenses/by/2.0), which permits unrestricted use, distribution, and reproduction in any medium, provided the original work is properly cited.

\begin{abstract}
Background: Huntington disease (HD) is an adult onset neurodegenerative disorder caused by a polyglutamine expansion in the huntingtin (htt) protein. Htt function is essential for embryonic survival as well as normal function during the postnatal period. In addition to having roles in transcription and transport, recent evidence demonstrates that wild-type htt is neuroprotective in vivo. To determine whether treatment with wild-type htt would be beneficial in HD, we crossed the YACI 28 mouse model of HD with mice that over-express wild-type htt (YACI8 mice) to generate YACI 28 mice that over-express wild-type htt (YACI8/I28 mice).

Results: YACI8/I28 mice were found to express mutant htt at the same level as YACI 28 mice and wild-type htt at the same level as YACl8 mice. YACI8/I28 mice show no significant behavioural improvement compared to $\mathrm{YACl} 28$ mice in the rotarod test of motor coordination or in an automated open field test. In the brain, YACI 8/I28 mice show no significant improvement in striatal volume, striatal neuronal numbers or striatal DARPP-32 expression compared to YACI 28 mice. In contrast, striatal neuronal cross-sectional area showed significant improvement in YACI 8/I28 mice compared to YACI 28 mice.
\end{abstract}

Conclusion: While the over-expression of wild-type htt results in a mild improvement in striatal neuropathology in YACI 28 mice, our findings suggest that treatment with wild-type htt may not be sufficient to ameliorate the symptoms of HD in this model.

\section{Background}

Huntington disease (HD) is an autosomal dominant disorder resulting from a trinucleotide CAG expansion in the HD gene. While the expression of mutant htt is sufficient to cause HD-like symptoms with normal expression levels of wild-type htt [1-3], recent data suggests that decreased levels of wild-type htt in HD patients may also contribute significantly to the pathogenesis of HD [4]. In support of this, we have recently demonstrated that the loss of wildtype htt in YAC128 mice significantly worsens motor performance, survival and striatal neuronal size [5]. 
Htt function is essential for development as mice homozygous for the targeted inactivation of the mouse HD gene are embryonic lethal [6-8]. Furthermore, decreasing htt levels by $50 \%$ or more from birth results in neurological abnormalities $[7,9,10]$. The expression of wild-type htt is also essential postnatally as mice expressing decreased levels of wild-type htt in the forebrain beginning at postnatal day 5 were shown to have a progressive neurological phenotype [11]. Clearly, decreased wild-type htt levels alone can lead to phenotypic abnormalities independent of mutant htt.

As the functions of wild-type htt become more clear, it seems that one of the most critical functions for htt may be in promoting neuronal survival. In vitro studies have demonstrated that the over-expression of wild-type htt protects cells against various insults including 3-nitroproprionic acid, a toxin which damages the striatum and has been used to model HD [12]. It has also been shown that over-expression of wild-type htt can specifically protect against polyglutamine toxicity in vitro [13]. This finding has been extended in vivo where increased expression of wild-type htt eliminated apoptotic degeneration in the testis caused by the expression of mutant htt $[5,14]$. The mechanism by which htt protects neurons may be direct by sequestration of the pro-apoptotic protein HIP-1 [15] or indirectly mediated through htt's effect on expression and transport within the cell as htt has been shown to be involved in both the transcription and movement of the brain derived neurotrophic factor [16-18]. In contrast, fragments of mutant htt have been shown to also protect against some forms of injury (excitotoxicity) through a different mechanism, likely the induction of a stress response [19].

In HD, there is evidence that striatal neurons die through excitotoxic mechanisms $[20,21]$. As such, we have previously examined the ability of htt to protect neurons in vivo against two different excitotoxic neurotoxins. For these experiments, we used YAC18 mice that over-express htt from a yeast artificial chromosome containing the entire human HD gene with 18 CAG repeats [22]. After intraperitoneal injection of kainic acid, YAC18 mice showed dramatically less neuronal loss in the hippocampus compared to WT controls [42]. Similarly, YAC18 mice showed significant, htt dose-dependent protection against lesions caused by intrastriatal injection of quinolinic acid [23].

Based on the clear demonstration of in vivo protection against excitotoxic cell death in YAC18 mice and the general protective effect of wild-type htt that has been demonstrated in vitro, we designed this experiment to determine if the over-expression of wild-type htt would be beneficial in treating HD. Since HD patients have at least a $50 \%$ genetic reduction in wild-type htt levels (resulting from the presence of at least one copy of the mutant HD gene), it is plausible that this decrease in htt's neuroprotective function will make neurons more susceptible to the toxicity of mutant htt. A decrease in wild-type htt levels may also affect htt's role in transcription and transport within the cell $[16-18,24]$. In fact many of htt's assayable functions have been shown to be disrupted by polyglutamine expansion $[12,16,17,23]$ and polyglutamine expansion also alters htt's ability to interact with its interacting proteins [24]. Thus, treatment of HD with wild-type htt may be beneficial by compensating for the loss of wild-type htt function and or through htt's general neuroprotective effect.

For this experiment we used the YAC128 mouse model of HD which recapitulates many aspects of the human disease $[3,25]$. These mice exhibit progressive motor dysfunction, cognitive impairment and selective neurodegeneration. YAC128 mice were crossed to YAC18 mice (which over-express full-length wild-type htt) to generate YAC128 mice that over-express wild-type htt (YAC18/128 mice). We show that over-expression of wild-type htt in YAC128 mice results in a mild improvement in striatal neuropathology but does not improve motor dysfunction.

\section{Results \\ Generation of YACI 28 mice that over-express wild-type huntingtin}

To determine whether wild-type htt could protect against mutant htt toxicity in the brain, we crossed YAC128 mice with YAC18 mice to generate YAC128 mice that overexpress wild-type htt (YAC18/128 mice). In order to maximize the amount of neuroprotection imparted by overexpression of wild-type htt, we used the highest expressing YAC18 line (line 212) available. We have previously shown that YAC18 line 212 mice express wild-type htt at $2-3$ times endogenous levels $[22,23,26]$ and exhibit the greatest degree of neuroprotection against quinolinic acid toxicity of all the YAC18 lines [23]. To confirm the high expression of htt in line 212 mice, we examined total wild-type huntingtin in line 212 and WT mice by Western blotting with polyclonal bkp1 antibody [27]. As previously reported, we found that line 212 mice express wildtype htt at levels that are more than two times the level of wild-type htt expression in WT mice (Fig. 1A, (WT: 0.386 \pm 0.014 arbitrary units, YAC18: $0.942 \pm 0.056$ arbitrary units, $\mathrm{p}=0.02$ ).

After breeding YAC18 and YAC128 mice together, YAC18/ 128 mice were generated in equal proportions to WT, YAC18 and YAC128 mice indicating normal embryonic survival. Since the YAC transgenes used to generate YAC18 and YAC128 mice express human htt, we examined transgenic htt expression with the human specific htt antibody, 


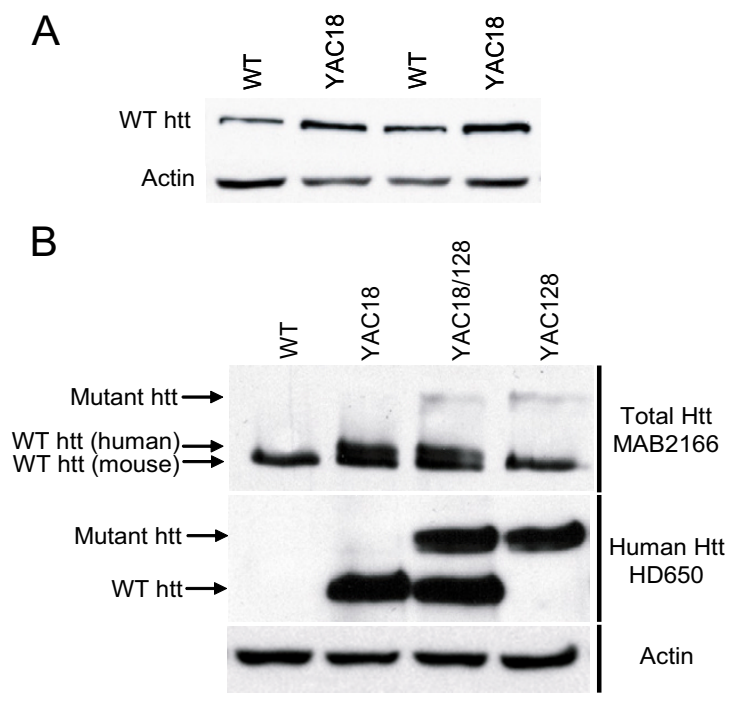

C

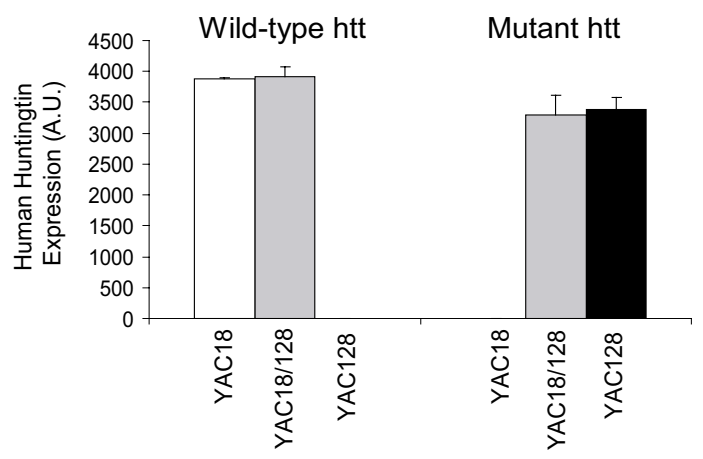

Figure I

Huntingtin expression in YAC I 8/ I 28 mice. YACI 8 and YACI 28 mice were crossed to generate YACI8/I28 mice. A. To confirm high levels of htt over-expression in YACI8, line 212 mice we performed Western blots on whole brain lysates. We found that line 212 mice have 2.4 times the levels of wild-type htt as WT mice (WT: $0.386 \pm 0.014$ arbitrary units, YAC I 8: $0.942 \pm 0.056$ arbitrary units, $P=0.02$ ). B. Total htt and human htt levels were assessed by Western blotting with MAB2 166 and HD650 antibody respectively. The human specific HD650 antibody was used to detect htt expressed from the YAC transgenes in YACI8, YACI 28 and YACI8/I 28 mice. Western blots performed with HD650 antibody indicate that YACI8//28 mice express both wildtype htt and mutant htt from YAC transgenes. As expected WT mice express no human htt, YACI 8 mice express only wild-type human htt and YACI 28 mice express only mutant human htt. Examination of total htt levels with MAB2166 antibody reveals that all mice express similar levels endogenous wild-type htt. C. Quantification of protein expression reveals that YACI8/I 28 mice express mutant htt at the same level as YACI 28 mice (YACI 28: $3389 \pm 197$ arbitrary units, YAC I8/I28: $3303 \pm 316$ arbitrary units, $p=0.8) . N=3$ mice per group. Error bars indicate standard error of the mean. A.U. = arbitrary units.
HD650 (Fig. 1B; [3]). We also examined total htt expression using MAB2166 which detects both mouse and human htt (Fig. 1B). As expected, WT mice (non-transgenic FVB/N) express wild-type mouse htt and no human htt. YAC18 mice express increased levels of wild-type htt which are accounted for by increased human htt expression. YAC128 mice express wild-type htt at the same level as WT mice and human mutant htt. Finally, YAC18/128 mice express increased levels of wild-type htt and mutant human htt. Importantly, the level of mutant htt expression was equal between the YAC128 and YAC18/128 mice indicating that the over-expression of wild-type htt did not down-regulate the expression of mutant htt (Fig. 1C; YAC128: $3389 \pm 197$ arbitrary units, YAC18/128: $3303 \pm$ 316 arbitrary units, $\mathrm{p}=0.8 ; \mathrm{N}=3$ ).

\section{Over-expression of wild-type huntingtin does not improve motor function in YACI 28 mice}

To examine the effect of wild-type htt on the motor dysfunction present in the YAC128 mice, we monitored motor coordination on the rotarod from 2 to 12 months of age. While ANOVA revealed an overall effect of genotype on rotarod performance (genotype: $\mathrm{F}_{(3,36)}=7.9$, $\mathrm{p}<$ $0.001, \mathrm{~N}=8 \mathrm{WT}, 9 \mathrm{YAC} 128,16 \mathrm{YAC} 18,8 \mathrm{YAC} 18 / 128)$, there were no significant differences between the YAC128 mice and YAC18/128 at any time point (YAC128: $147 \pm$ 13 seconds, YAC18/128: $134 \pm 14$ seconds, $\mathrm{p}^{\text {YAC128vsYAC18/ }}$ $128=0.5$, YAC18: $164 \pm 19$ seconds). Both groups performed significantly worse than WT mice (WT: $227 \pm 15$ seconds, $\mathrm{p}<0.001)$.

We have previously reported early hyperactivity and late hypoactivity in YAC128 mice compared to WT mice [3,5]. As such, we compared the activity of YAC18/128 mice and YAC128 mice at 2 and 12 months of age to determine if wild-type htt expression could ameliorate the abnormal activity pattern present in YAC128 mice. We observed no significant improvement in activity in YAC18/128 mice compared to YAC128 mice (2 months - YAC128: $334 \pm$ 13 beam breaks, YAC18/128: $320 \pm 12$ beam breaks, $\mathrm{p}^{\mathrm{YAC} 128 \mathrm{vSYAC} 18 / 128}=0.5$, YAC18: $324 \pm 11$ beam breaks; 12 months - YAC128: $274 \pm 19$ beam breaks, YAC18/128: $289 \pm 15$ beam breaks, p $^{\mathrm{YAC} 128 \mathrm{vSYAC} 18 / 128}=0.5$, YAC18: $277 \pm 11 ; \mathrm{N}=8 \mathrm{WT}, 9$ YAC128, 16 YAC18, 8 YAC18/128). Overall, increasing wild-type htt expression did not provide a significant behavioural benefit to YAC128 mice.

While this study was not powered to demonstrate significant differences in survival, the number of YAC18/128 mice surviving to 12 months was similar to what we normally observe in YAC128 mice [Table 1; 12 month survival - WT males: 91\%, YAC128 males: 73\%, YAC18/128 males: 73\% (8 of 11 mice), WT females: 90\%, YAC128 females: 93\%, YAC18/128 females: 100\% (4 of 4 mice)]. 
Table I: Effect of modulating wild-type huntingtin levels on survival in YACI 28 mice.

\begin{tabular}{|c|c|c|c|c|}
\hline Sex & Genotype & Deaths & Total Mice & Percent Surviving \\
\hline \multirow[t]{4}{*}{ Males } & WT & 4 & 46 & $91 \%$ \\
\hline & YACI8/I28 & 3 & I I & $73 \%$ \\
\hline & YACI 28 & 12 & 48 & $75 \%$ \\
\hline & YACI 28-/- & 11 & 15 & $27 \%$ \\
\hline \multirow[t]{4}{*}{ Females } & WT & 5 & 42 & $88 \%$ \\
\hline & YACI 8/I 28 & 0 & 4 & $100 \%$ \\
\hline & YACI 28 & 5 & 66 & $92 \%$ \\
\hline & YACI28-/- & 3 & 19 & $84 \%$ \\
\hline
\end{tabular}

YACI28-/- mice express mutant htt and no wild-type htt. YACI 28 mice express mutant htt and 2 copies of wild-type htt. YACI8/I28 express mutant htt and increased levels of wild-type htt.

Mice surviving to 12 months of age were sacrificed and we examined brain and testicular weight as these have been shown to be decreased in YAC128 mice $[3,5]$. In both cases, there was a significant difference between YAC128 and WT mice which was not improved by the over-expression of wild-type htt (Brain weight - WT: $403 \pm 7 \mathrm{mg}$, YAC18: $402 \pm 4 \mathrm{mg}$, YAC128: $384 \pm 4 \mathrm{mg}$, YAC18/128: $382 \pm 3 \mathrm{mg}, \mathrm{p}^{\mathrm{YAC} 128 \mathrm{vSYAC} 18 / 128}=0.6, \mathrm{~N}=17 \mathrm{WT}, 17$ YAC128, 14 YAC18, 17 YAC18/128; Testis weight - WT: $164 \pm 5 \mathrm{mg}$, YAC18: $152 \pm 7 \mathrm{mg}$, YAC128: $142 \pm 5 \mathrm{mg}$, YAC18/128: $123 \pm 4 \mathrm{mg}, \mathrm{p}^{\mathrm{YAC} 128 \mathrm{v} Y A C 18 / 128}=0.01, \mathrm{~N}=7$ WT, 8 YAC128, 10 YAC18, 10 YAC18/128). Unexpectedly, the testicular weight in YAC18/128 mice was significantly less than in YAC128 mice and there was a trend towards decreased testicular weight in YAC18 mice compared to WT. This suggests the possibility that high levels of htt expression may be detrimental in the testis.

\section{Over-expression of wild-type huntingtin results in mild improvement in striatal neuropathology in YACI 28 mice}

YAC128 mice demonstrate clear striatal neuropathology at 12 months of age with decreased striatal volume, striatal neuronal loss, striatal neuronal atrophy and decreased striatal DARPP-32 expression $[3,28]$. To determine whether the expression of wild-type htt could ameliorate these striatal phenotypes we examined the striata of YAC18/128 mice. Comparing YAC18/128 mice and YAC128 mice revealed no significant improvement in striatal volume (Fig. 2A; YAC128: $11.3 \pm 0.2 \mathrm{~mm}^{3}$, YAC18/ 128: $11.6 \pm 0.2 \mathrm{~mm}^{3}, \mathrm{p}^{\mathrm{YAC} 128 \mathrm{vs} \mathrm{YCC} 18 / 128}=0.3, \mathrm{YAC} 18=$ $12.5 \pm 0.3 \mathrm{~mm}^{3} ; \mathrm{N}=17 \mathrm{WT}, 17 \mathrm{YAC} 128,14 \mathrm{YAC} 18,17$ YAC18/128), striatal neuronal numbers (Fig. 2B; YAC128: $1.56 \pm 0.03$ million neurons, YAC18/128: $1.59 \pm 0.03$ million neurons, $\mathrm{p}=0.4$, YAC18: $1.64 \pm 0.03$ million neurons; $\mathrm{N}=17 \mathrm{WT}, 17$ YAC128, 14 YAC18, 17 YAC18/128) or striatal DARPP-32 expression (Fig. 2C; YAC128: $828 \pm$ 28 arbitrary units, YAC18/128: $868 \pm 22$ arbitrary units, $\mathrm{p}^{\mathrm{YAC} 128 \mathrm{vs} Y A C 18 / 128}=0.3, \mathrm{YAC} 18: 1012 \pm 19$ arbitrary units; $\mathrm{N}=10 \mathrm{WT}, 12$ YAC128, 10 YAC18, 8 YAC18/128) with increased wild-type htt expression. In each case, YAC128 mice showed significant abnormalities compared to WT mice. In contrast, increasing wild-type htt expression in YAC128 mice resulted in a significant reduction in striatal neuronal atrophy (Fig. 2D; YAC128: $96.2 \pm 1.6 \mathrm{um}^{2}$, YAC18/128: $108 \pm 1.9 \mathrm{um}^{2}, \mathrm{p}^{\mathrm{YAC} 128 \mathrm{v} Y \mathrm{YAC} 18 / 128}<0.001$, YAC18: $110 \pm 1.7 \mathrm{um}^{2} ; \mathrm{N}=17 \mathrm{WT}, 17 \mathrm{YAC} 128,14$ YAC18, 17 YAC18/128) with the striatal neuronal crosssectional area in YAC18/128 mice being almost restored to wild-type (WT: $110 \pm 3 \mathrm{um}^{2}, \mathrm{p}=0.6$ ).

\section{Discussion}

Based on recent work demonstrating a neuroprotective function of wild-type htt and suggestions that loss of wildtype htt function contributes to HD pathogenesis, we investigated the therapeutic potential of wild-type htt in the YAC128 mouse model of HD. We found that overexpression of wild-type htt in YAC128 mice resulted in a mild improvement in striatal neuropathology with no significant improvement in behavioural phenotypes.

The effect of over-expression of wild-type htt in YAC128 mice is summarized in table 2. A robust finding of this study was that over-expression of wild-type htt in YAC128 mice restored striatal neuronal size. Similarly, we have found that decreasing wild-type htt levels in YAC128 mice results in decreased neuronal size [5]. Combined, these results suggest that wild-type htt levels influence neuronal size and suggest that loss of wild-type htt may contribute to the striatal neuronal atrophy observed in HD. An alternate possibility is that striatal neuronal size is more responsive to mildly beneficial effects of treatments as this measure has been shown to exhibit the most dramatic improvements in therapeutic trials in mouse models of HD [29-31]. The effect of wild-type htt on neuronal size may be related to htt's ability to increase BDNF transcription [17] and transport [16] since BDNF promotes the survival and differentiation of striatal neurons.

In contrast to the significant improvement in striatal neuronal size, there was no significant effect of wild-type htt 

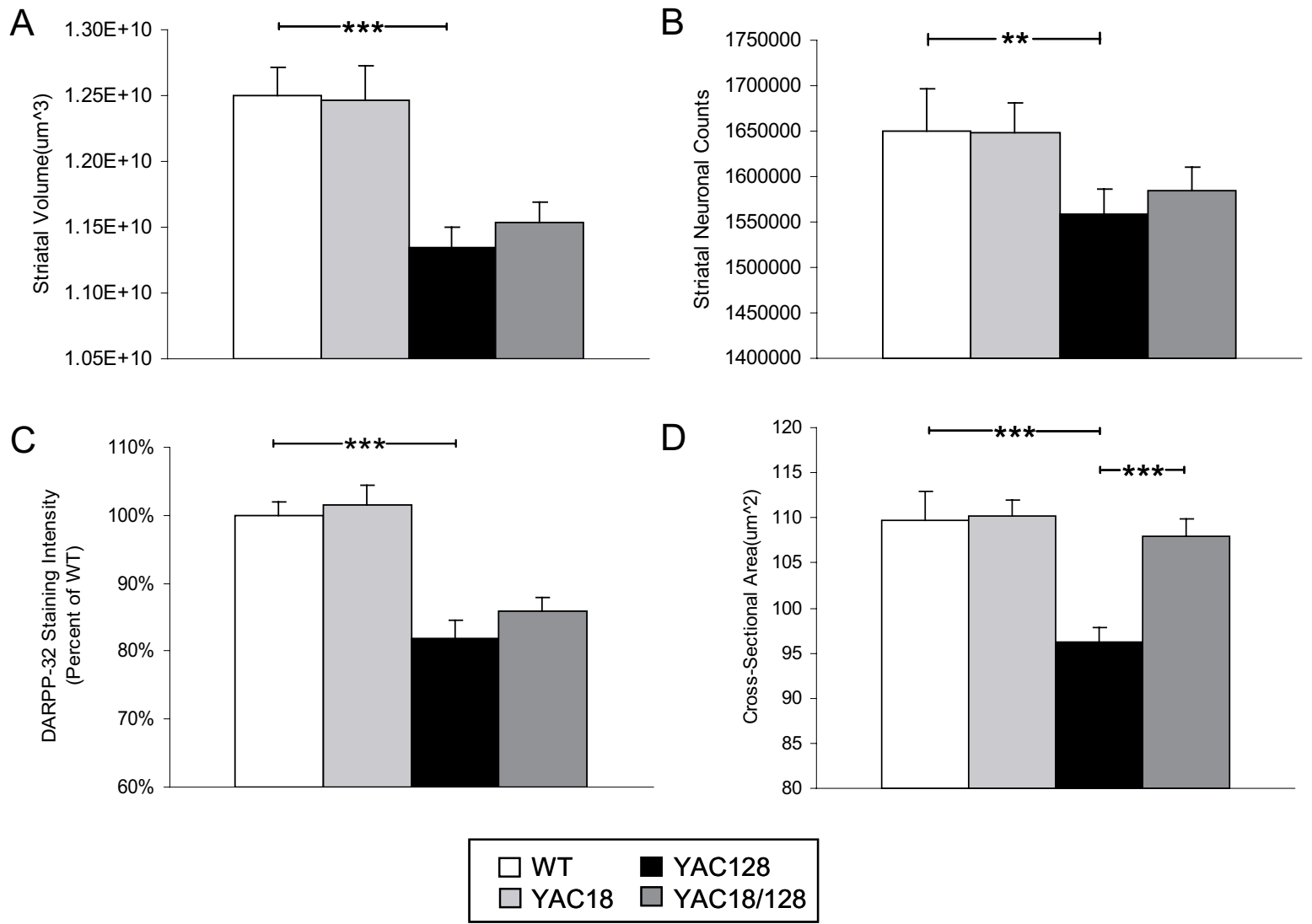

Figure 2

Over-expression of wild-type htt results in mild improvements in striatal neuropathology in YACI28 mice. Comparison of striatal phenotypes between YACI 28 and YACI8/I 28 mice revealed that over-expression of wild-type htt resulted in no significant change in striatal volume (panel A: YACI28: II $.3 \pm 0.2 \mathrm{~mm}^{2}, Y A C I 8 / 128: 11.6 \pm 0.2 \mathrm{~mm}{ }^{2}, p=0.3$ ), striatal neuronal counts (panel B: YACI28: $1.56 \pm 0.03$ million neurons, $Y A C I 8 / I 28$ : $1.59 \pm 0.03$ million neurons, $P=0.4$ ) or striatal DARPP-32 expression (panel C: YACI28: $828 \pm 28$ arbitrary units, YACI8/I28: $868 \pm 22$ arbitrary units, $P=0.3$ ). In contrast, over-expression of wild-type htt resulted in a significant improvement in striatal neuronal cross-sectional area (panel

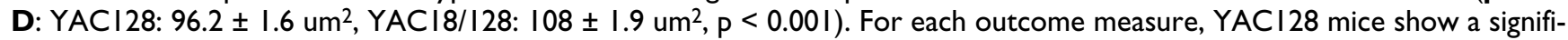
cant deficit compared to WT mice. $\mathrm{N}=17 \mathrm{WT}$, 17 YACI28, 14 YAC 18, 17 YAC I8/128 except for striatal DARPP-32 expression where $\mathrm{N}=10 \mathrm{WT}, 12 \mathrm{YACI} 28,10 \mathrm{YACI} 8,8 \mathrm{YACI} 8 / 128$. Error bars show standard error of the mean. $* * \mathrm{p}<0.01$. *** $\mathrm{p}<0.001$.

over-expression on open field activity, striatal volume, striatal neuronal counts or striatal DARPP-32 levels in YAC128 mice, despite a trend towards improvement. In parallel with these experiments we examined the effect of eliminating wild-type htt expression in YAC128 mice and found that there was a trend towards decreased striatal volume, striatal neuronal counts and striatal DARPP-32 expression which did not reach significance [5] (see Additional file 1 for summary). It is possible that the 12 month time point chosen to assess neuropathology in these experiments was too late in the disease process and that differences in severity were masked by a ceiling effect or that we have missed differences in the onset of striatal neuropathology.
In our previous study we observed a significant increase of both rotarod performance and survival when wild-type htt levels were increased in YAC128 -/- mice to wild-type levels [5]. In this experiment, we did not observe any further improvement in either rotarod performance or survival with the over-expression of wild-type htt suggesting that there may be ceiling effect for the amount that wildtype htt can improve these outcome measures. While this study did not have enough power to demonstrate a significant improvement in survival, the fact that the percentage of mice surviving to 12 months was similar to YAC128 mice suggests that the over-expression of wild-type huntingtin does not have a dramatic effect on survival in YAC128 mice. The survival deficit in the YAC128 and 
Table 2: Effect of over-expression of wild-type huntingtin on HD-like phenotypes in the YACI 28 mouse model of HD.

\begin{tabular}{|c|c|c|c|c|}
\hline Phenotype & $\begin{array}{c}\text { Percent Difference } \\
\text { YACI } 28 \text { Compared to } \\
\text { WT }\end{array}$ & $\begin{array}{c}\text { Percent Difference } \\
\text { YAC I8/I } 28 \text { Compared } \\
\text { to WT }\end{array}$ & $\begin{array}{l}\text { Percent Rescue with } \\
\text { WT htt Expression }\end{array}$ & Significance \\
\hline Rotarod & $-36 \%$ & $-41 \%$ & None & $p=0.5$ \\
\hline Activity - 2 Months & $+6 \%$ & $+2 \%$ & $74 \%$ & $P=0.5$ \\
\hline Activity - 12 Months & $-10 \%$ & $-6 \%$ & $47 \%$ & $P=0.5$ \\
\hline Striatal Volume & $-9 \%$ & $-7 \%$ & $21 \%$ & $p=0.3$ \\
\hline Striatal Neuronal Counts & $-6 \%$ & $-3 \%$ & $38 \%$ & $p=0.4$ \\
\hline $\begin{array}{l}\text { Striatal DARPP-32 } \\
\text { Expression }\end{array}$ & $-18 \%$ & $-14 \%$ & $22 \%$ & $p=0.3$ \\
\hline Striatal Neuronal Size & $-12 \%$ & $-2 \%$ & $87 \%$ & $P<0.001$ \\
\hline
\end{tabular}

YAC18/128 mice were only observed in male mice thus confirming our previous observations [5]. Unexpectedly, we found that increasing wild-type huntingtin expression in YAC128 mice resulted in further decreases in testicular mass. Combined with a trend towards decreased testicular mass in YAC18 mice, this suggests the possibility that expression of htt beyond a certain threshold may result in testicular atrophy which is exacerbated by the presence of mutant htt. It is also possible that the human origin of the over-expressed htt contributes to the testicular phenotype. Unfortunately, we are not aware of a mouse model that over-expresses wild-type mouse htt at high levels that would permit testing of this hypothesis.

In this study, we used the YAC128 mouse model of HD which transgenically expresses mutant huntingtin at approximately $75 \%$ of endogenous levels [3]. These mice have two intact copies of the wild-type HD gene and we have previously shown that they express wild-type htt at the same level as WT mice [5]. As such, YAC128 mice express higher levels of wild-type htt protein than patients with HD. The fact that the levels of wild-type htt are already increased in YAC128 mice may diminish the therapeutic benefit we observe in YAC18/128 mice by further over-expressing wild-type htt. To more directly assess the therapeutic benefit of wild-type htt in HD, one could over-express mouse wild-type htt in a knockin mouse model of HD to assess the effect of wild-type htt on early disease phenotypes in these mice.

The results of this study are congruent with comparisons of homozygous and heterozygous HD patients and HD mouse models which suggest that mutant htt has a greater influence on the disease phenotype than wild-type htt. Examination of disease severity in patients homozygous and heterozygous for mutations in the HD gene have reported either no difference or that homozygous HD patients are more severely affected [32-37]. Two independent studies have also examined the phenotype of mice that are homozygous for a targeted expansion of the HD gene (HD knock-in mice). In both cases, homozygous
HD knock-in mice exhibited a more severe phenotype than heterozygous HD knock-in mice, but the differences were mild $[38,39]$. These studies suggest that mutant htt maintains many of the critical functions of wild-type htt as replacement of wild-type htt with mutant htt has only a mild effect on phenotype. However, it has been shown that polyglutamine expansion disrupts htt's neuroprotective function $[12,23]$, at least part of htt's role in transcription [17] and transport [16], and also affects the interaction of htt with its interaction partners [24]. Since increasing mutant htt expression alone is known to result in a more severe phenotype in mice [40], it suggests that the increase in phenotypic severity between heterozygous and homozygous patients and animal models is mainly caused by the increase in mutant htt levels which is in line with our findings that increasing levels of wild-type htt has only a small impact on the disease phenotype.

These findings are surprising given the importance of htt function and its demonstrated neuroprotective abilities. $\mathrm{Htt}$ is essential for embryonic development and decreases in htt expression alone lead to abnormal phenotypes [6$8,10,11,41]$. Further, htt has been shown to protect cells from death both in vitro and in the testis and in the brain $[12-14,23]$. While htt has been shown to specifically protect against polyglutamine toxicity both in vitro [13] and in the testis $[5,14]$, our findings here indicate a milder protective effect against mutant htt toxicity in the brain. Given that wild-type htt exhibits protection against excitotoxic neurotoxins [23], our finding that wild-type htt mildly improves striatal neuropathology in YAC128 mice is not inconsistent with excitotoxicity contributing to the pathogenesis of HD.

\section{Conclusion}

Overall, our results demonstrate that the over-expression of wild-type htt in YAC128 mice results in a mild improvement in striatal neuropathology. Based on the clear effect of htt over-expression on striatal neuronal size, it appears that htt function may be important in maintaining neuronal health. Despite the protective function of 
wild-type htt, our results suggest that mutant htt toxicity is primarily responsible for the pathognomic striatal neuropathology in HD and that treatment of HD with wildtype htt may not be sufficient to ameliorate the symptoms of the disease.

\section{Methods \\ Mice}

YAC18 and YAC128 mice that express human wild-type or mutant htt from a yeast artificial chromosome and wildtype littermates were used for these experiments [3,22]. For YAC18 mice, we used the high-expressing line 212 which expresses wild-type htt at 2-3 times endogenous levels [22]. Mice were maintained on the FVB/N (Charles River, Wilmington, MA) background strain. Mice were group housed with a normal light-dark cycle (lights on at 6:00 AM, lights off at 8:00 PM) in a clean facility and given free access to food and water. All experiments were carried out in accordance with protocols approved by the UBC Committee on Animal Care and the Canadian Council on Animal Care. The results shown are the combined results from male and female mice. We examined the data for both sexes separately and found no differences from the combined results.

\section{Behavioural analysis}

Motor coordination was assessed on an accelerating rotarod (UGO Basile, Comerio, Italy) as previously described [5]. After training at 2 months, mice were tested bimonthly from 2 to 12 months of age with a maximum score for each trial of 300 seconds. Open field activity was assessed in an automated open field apparatus (San Diego Instruments, San Diego, California). Activity was measured at 2 months and at 12 months during a ten minute open field trial. Activity was measured as the number of beam crosses in the trial. Clean cages were used for each trial. For behavioural assessment we used 8 WT ( 5 F, $3 \mathrm{M})$, 9 YAC128 (5 F, 4 M), 16 YAC18 (9 F, 7 M) and 8 YAC18/ 128 (3 F, $5 \mathrm{M})$ mice.

\section{Western blotting}

Protein levels were measured from homogenized whole brain lysates from a total of 3 mice per genotype. A lowbis acrylamide gel was run with $100 \mu \mathrm{g}$ of total protein per sample for a total of 600 volt-hours. Proteins were transferred to a membrane at 24 volts for 1.5 hours. Blots were then probed with antibodies for either total htt (MAB2166, Chemicon, Temecula, California) or specifically human htt [HD650, (Slow et al., 2003a)] followed by an anti-mouse, peroxidase-conjugated secondary antibody before enhanced chemiluminescent detection. Protein levels were quantified using Quantity One software (Biorad, Hercules, CA).

\section{Neuropathology}

Neuropathology was carried out on 17 WT (11 F, $6 \mathrm{M}), 17$ YAC128 (10 F, 7 M), 14 YAC18 (8 F, 6 M) and 17 YAC18/ 128 (8 F, $9 \mathrm{M}$ ) mice. Mice were perfused with 3\% paraformaldehyde in phosphate buffered saline. Brains and testis were post-fixed in 3\% paraformaldehyde for 24 hours and then equilibrated with PBS prior to weighing. Subsequently, brains were infiltrated with sucrose $(25 \%$ in PBS), frozen and sectioned on a cryostat (Microm HM 500 M, Richard-Allan Scientific, Calamazoo, Michigan).

A series of $25 \mu \mathrm{m}$ coronal sections spaced $200 \mu \mathrm{m}$ apart were stained with NeuN primary antibody (1:100 dilution in 5\% NGS, $0.1 \%$ T-X-100, PBS; Chemicon) overnight at room temperature, biotinylated anti-mouse secondary antibody (1:200 dilution in 1\% NGS, 0.1\% T-X-100, PBS) for 2 hours at room temperature and incubated in $\mathrm{ABC}$ reagent (ABC Elite kit, Vector) for 2 hours at room temperature before detection with metal-enhanced DAB solution (Pierce, Rockford, Illinois).

Striatal volume was determined using Stereoinvestigator software (Microbrightfield, Williston, Virginia). Briefly, the perimeter of the striatum was traced using a $2.5 \mathrm{X}$ objective in each section of the coronal series and the software calculated the volume of the entire structure. Subsequently, neuronal profiles in a $25 \mu \mathrm{m} \times 25 \mu \mathrm{m}$ counting frame were counted with a $550 \mu \mathrm{m}$ by $550 \mu \mathrm{m}$ grid for all grids the fell within the outlined areas. The counts were then extrapolated to estimate the total number of neurons in the striatum. To determine neuronal cross-sectional areas, a single matched section from each animal was stained with an Alexa488-conjugated NeuN antibody (Chemicon). Mounted sections were analyzed using Stereoinvestigator to outline the perimeter of all clearly defined neurons within a $550 \mu \mathrm{m} \times 550 \mu \mathrm{m}$ grid of $25 \mu \mathrm{m}$ $\times 25 \mu \mathrm{m}$ counting frames with the 100X objective. On average 32 neurons per mouse were assessed for a total of more than 450 neurons per genotype.

For measurement of DARPP-32 expression, sections were stained with rabbit anti-DARPP-32 antibody (Chemicon $\mathrm{AB}$ 1656, 1:1000). After 3 washes with PBS, sections were incubated in Cy3-conjugated goat anti-rabbit antibody (1:500; Jackson ImmunoResearch Inc., West Grove, Pennsylvania). Pictures of mounted sections were taken using MetaMorph Imaging System (Molecular Devices, Downingtown, Pennsylvania) and the intensity of the fluorescent stain within the striatum was measured. $10 \mathrm{WT}, 12$ YAC128, 10 YAC18 and 8 YAC18/128 were used for this analysis.

Immunohistochemistry for markers of neuronal health was performed as described above using the following antibodies: synaptophysin (1:100; BD Transduction Lab- 
oratories, Mississauga, Ontario), calbindin (1:2000; provided by Ken Bainbridge, University of British Columbia, Canada), EM48 (1:500; provided by Xiao-Jiang Li, Emory University, U.S.A) and 8-hydroxy-2-deoxyguanosine (1:500; Japan Institute for the Control of Aging, Fukuroi City, Japan).

\section{Statistical analysis}

Overall effects of genotype were determined by one way ANOVA. Repeated measures ANOVA analysis was used for analysis of differences in rotarod performance. The significance of differences between YAC128 and YAC18/128 mice was determined by either the Tukey post-hoc test following ANOVA or a student's t-test.

\section{Authors' contributions}

JVR conceived the study, designed the experiment, completed the neuropathological assessment of the mice except for the striatal DARPP-32 levels, carried out the Western blot for human htt, prepared the figures for the manuscript and wrote the manuscript. JP carried out the behavioural analysis including rotarod and open field testing. ZM completed the western blot for total htt. MRH and BRL contributed to the conception and design of the experiment and were also involved in editing the manuscript. All of the authors have read and approved the final manuscript.

\section{Additional material}

\section{Additional File 1}

Supplemental Table 1. This table summarizes the effect of increasing or decreasing wild-type huntingtin levels on phenotypic severity in the YAC128 mouse model of Huntington disease

Click here for file

[http://www.biomedcentral.com/content/supplementary/14712202-7-80-S1.eps]

\section{Acknowledgements}

We would like to thank Daniel Rogers, Nagat Bissada, Kuljeet Vaid and Ge Lu for their technical assistance. This work was supported by grants from the Huntington's Disease Society of America, the High Q Foundation and the Huntington Society of Canada. JVR has been supported by the Canadian Institutes of Health Research, the Michael Smith Foundation for Health Research and the Huntington Society of Canada. BRL and MRH are supported by the Canadian Institutes of Health Research, the Huntington Society of Canada, the Hereditary Disease Foundation and the Canadian Genetic Diseases Network. MRH is a Killam University Professor and holds a Canada Research Chair in Human Genetics.

\section{References}

I. Hodgson JG, Agopyan N, Gutekunst CA, Leavitt BR, LePiane F, Singaraja R, et al: A YAC mouse model for Huntington's disease with full-length mutant huntingtin, cytoplasmic toxicity, and selective striatal neurodegeneration. Neuron 1999, 23: 18I-192.
2. Reddy PH, Williams M, Charles V, Garrett L, Pike-Buchanan L, Whetsell WO Jr, et al:: Behavioural abnormalities and selective neuronal loss in HD transgenic mice expressing mutated fulllength HD cDNA. Nat Genet 1998, 20:198-202.

3. Slow EJ, van Raamsdonk J, Rogers D, Coleman SH, Graham RK, Deng $Y$, et al: Selective striatal neuronal loss in a YACI 28 mouse model of Huntington disease. Hum Mol Genet 2003, I 2: I555-1567.

4. Cattaneo E, Rigamonti D, Goffredo D, Zuccato C, Squitieri F, Sipione $S$ : Loss of normal huntingtin function: new developments in Huntington's disease research. Trends Neurosci 200I, 24:182-188.

5. Van Raamsdonk JM, Pearson J, Rogers DA, Bissada N, Vogl AW, Hayden MR, et al:: Loss of wild-type huntingtin influences motor dysfunction and survival in the YACI28 mouse model of Huntington disease. Hum Mol Genet 2005, 14:1379-1392.

6. Duyao MP, Auerbach AB, Ryan A, Persichetti F, Barnes GT, McNeil SM, et al.: Inactivation of the mouse Huntington's disease gene homolog Hdh. Science 1995, 269:407-4I0.

7. Nasir J, Floresco SB, O'Kusky JR, Diewert VM, Richman JM, Zeisler J, et al:: Targeted disruption of the Huntington's disease gene results in embryonic lethality and behavioral and morphological changes in heterozygotes. Cell 1995, 81:8II-823.

8. Zeitlin S, Liu JP, Chapman DL, Papaioannou VE, Efstratiadis A: Increased apoptosis and early embryonic lethality in mice nullizygous for the Huntington's disease gene homologue. Nat Genet 1995, I I:155-163.

9. O'Kusky JR, Nasir J, Cicchetti F, Parent A, Hayden MR: Neuronal degeneration in the basal ganglia and loss of pallido-subthalamic synapses in mice with targeted disruption of the Huntington's disease gene. Brain Res 1999, 81 8:468-479.

10. White JK, Auerbach W, Duyao MP, Vonsattel JP, Gusella JF, Joyner $\mathrm{AL}$, et al.: Huntingtin is required for neurogenesis and is not impaired by the Huntington's disease CAG expansion. Nat Genet 1997, 17:404-4I0.

II. Dragatsis I, Levine MS, Zeitlin S: Inactivation of Hdh in the brain and testis results in progressive neurodegeneration and sterility in mice. Nat Genet 2000, 26:300-306.

12. Rigamonti D, Bauer JH, De Fraja C, Conti L, Sipione S, Sciorati C, et al.: Wild-type huntingtin protects from apoptosis upstream of caspase-3. J Neurosci 2000, 20:3705-37/3.

13. Ho LW, Brown R, Maxwell M, Wyttenbach A, Rubinsztein DC: Wild type Huntingtin reduces the cellular toxicity of mutant Huntingtin in mammalian cell models of Huntington's disease. J Med Genet 200I, 38:450-452.

14. Leavitt BR, Guttman JA, Hodgson JG, Kimel GH, Singaraja R, Vogl $\mathrm{AW}$, et al.: Wild-type huntingtin reduces the cellular toxicity of mutant huntingtin in vivo. Am J Hum Genet 200I, 68:3I3-324.

15. Hackam AS, Yassa AS, Singaraja R, Metzler M, Gutekunst CA, Gan L, et al.: Huntingtin interacting protein $I$ induces apoptosis via a novel caspase-dependent death effector domain. J Biol Chem 2000, 275:4I 299-4I308.

16. Gauthier LR, Charrin BC, Borrell-Pages M, Dompierre JP, Rangone H, Cordelieres FP, et al.: Huntingtin controls neurotrophic support and survival of neurons by enhancing BDNF vesicular transport along microtubules. Cell 2004, I I 8: I27-I38.

17. Zuccato C, Ciammola A, Rigamonti D, Leavitt BR, Goffredo D, Conti $L$, et al.: Loss of huntingtin-mediated BDNF gene transcription in Huntington's disease. Science 200I, 293:493-498.

18. Zuccato C, Tartari M, Crotti A, Goffredo D, Valenza M, Conti L, et al.: Huntingtin interacts with REST/NRSF to modulate the transcription of NRSE-controlled neuronal genes. Nat Genet 2003, 35:76-83.

19. Hansson O, Petersen A, Leist M, Nicotera P, Castilho RF, Brundin P: Transgenic mice expressing a Huntington's disease mutation are resistant to quinolinic acid-induced striatal excitotoxicity. Proc Natl Acad Sci USA 1999, 96:8727-8732.

20. Bezprozvanny I, Hayden MR: Deranged neuronal calcium signaling and Huntington disease. Biochem Biophys Res Commun 2004, 322: $1310-1317$.

21. Tabrizi SJ, Cleeter MW, Xuereb J, Taanman JW, Cooper JM, Schapira $\mathrm{AH}$ : Biochemical abnormalities and excitotoxicity in Huntington's disease brain. Ann Neurol 1999, 45:25-32.

22. Hodgson JG, Smith DJ, McCutcheon K, Koide HB, Nishiyama K, Dinulos MB, et al: Human huntingtin derived from YAC transgenes 
compensates for loss of murine huntingtin by rescue of the embryonic lethal phenotype. Hum Mol Genet 1996, 5: I 875- I 885.

23. Leavitt BR, van Raamsdonk JM, Shehadeh J, Fernandes HB, Murphy Z, Graham RK, Raymond LA, Hayden MR: Wild-type huntingtin protects neurons from excitotoxicity. I Neurochem 2006, 96(4): $|12|-9$.

24. $\mathrm{Li} \mathrm{SH}, \mathrm{Li} \mathrm{XJ}$ : Huntingtin-protein interactions and the pathogenesis of Huntington's disease. Trends Genet 2004, 20: I 46-I54.

25. Van Raamsdonk JM, Pearson J, Slow EJ, Hossain SM, Leavitt BR, Hayden MR: Cognitive dysfunction precedes neuropathology and motor abnormalities in the YACI 28 mouse model of Huntington's disease. J Neurosci 2005, 25:4169-4I80.

26. Van Raamsdonk JM, Gibson WT, Pearson J, Murphy Z, Lu G, Leavitt $B R$, et al.: Body weight is modulated by levels of full-length Huntingtin. Hum Mol Genet 2006, I5:15/3-1523.

27. Kalchman MA, Graham RK, Xia G, Koide HB, Hodgson JG, Graham $\mathrm{KC}$, et al:: Huntingtin is ubiquitinated and interacts with a specific ubiquitin-conjugating enzyme. I Biol Chem 1996, 27I: 19385-19394.

28. Van Raamsdonk JM, Pearson J, Rogers DA, Lu G, Barakauskas VE, Barr AM, et al:: Ethyl-EPA treatment improves motor dysfunction, but not neurodegeneration in the YACI 28 mouse model of Huntington disease. Exp Neurol 2005, 196:266-272.

29. Ferrante RJ, Kubilus JK, Lee J, Ryu H, Beesen A, Zucker B, et al.: Histone deacetylase inhibition by sodium butyrate chemotherapy ameliorates the neurodegenerative phenotype in Huntington's disease mice. J Neurosci 2003, 23:9418-9427.

30. Ferrante RJ, Ryu H, Kubilus JK, D'Mello S, Sugars KL, Lee J, et al.: Chemotherapy for the brain: the antitumor antibiotic mithramycin prolongs survival in a mouse model of Huntington's disease. I Neurosci 2004, 24:10335-10342.

3I. Gardian G, Browne SE, Choi DK, Klivenyi P, Gregorio J, Kubilus JK, et al:: Neuroprotective effects of phenylbutyrate in the NI7I$82 \mathrm{Q}$ transgenic mouse model of Huntington's disease. I Biol Chem 2005, 280:556-563.

32. Durr A, Hahn-Barma V, Brice A, Pecheux C, Dode C, Feingold J: Homozygosity in Huntington's disease. J Med Genet 1999, 36:172-173

33. Kremer B, Goldberg P, Andrew SE, Theilmann J, Telenius H, Zeisler J, et al:: A worldwide study of the Huntington's disease mutation. The sensitivity and specificity of measuring CAG repeats. $N$ Engl | Med 1994, 330: | 40 I-I 406.

34. Laccone F, Engel U, Holinski-Feder E, Weigell-Weber M, Marczinek K, Nolte D, et al:: DNA analysis of Huntington's disease: five years of experience in Germany, Austria, and Switzerland. Neurology 1999, 53:80I-806.

35. Myers RH, Leavitt J, Farrer LA, Jagadeesh J, McFarlane H, Mastromauro CA, et al: Homozygote for Huntington disease. Am J Hum Genet 1989, 45:615-618.

36. Squitieri F, Gellera C, Cannella M, Mariotti C, Cislaghi G, Rubinsztein DC, et al.: Homozygosity for CAG mutation in Huntington disease is associated with a more severe clinical course. Brain 2003, I 26:946-955.

37. Wexler NS, Young AB, Tanzi RE, Travers H, Starosta-Rubinstein $S$, Penney JB, et al.: Homozygotes for Huntington's disease. Nature 1987, 326:194-197.

38. Lin CH, Tallaksen-Greene S, Chien WM, Cearley JA, Jackson WS, Crouse $A B$, et al: Neurological abnormalities in a knock-in mouse model of Huntington's disease. Hum Mol Genet 200I, 10:137-144.

39. Wheeler VC, White JK, Gutekunst CA, Vrbanac V, Weaver M, Li XJ, et al: Long glutamine tracts cause nuclear localization of a novel form of huntingtin in medium spiny striatal neurons in HdhQ92 and HdhQIII knock-in mice. Hum Mol Genet 2000, 9:503-5।3.

40. Graham RK, Slow EJ, Deng Y, Bissada N, Lu G, Pearson J, et al.: Levels of mutant huntingtin influence the phenotypic severity of Huntington disease in YACI 28 mouse models. Neurobiol Dis 2006, 21 : 444-455.

4I. Auerbach W, Hurlbert MS, Hilditch-Maguire P, Wadghiri YZ, Wheeler VC, Cohen SI, et al.: The HD mutation causes progressive lethal neurological disease in mice expressing reduced levels of huntingtin. Hum Mol Genet 200I, 10:25I5-2523.

42. Zhang Y, Leavitt BR, van Raamsdonk JM, Dragatsis I, Goldowitz D, Macdonald ME, Hayden MR, Friedlander RM: Huntingtin inhibits caspase-3 activation. EMBO J 2006. [Epub ahead of print]
Publish with Bio Med Central and every scientist can read your work free of charge

"BioMed Central will be the most significant development for disseminating the results of biomedical research in our lifetime. "

Sir Paul Nurse, Cancer Research UK

Your research papers will be:

- available free of charge to the entire biomedical community

- peer reviewed and published immediately upon acceptance

- cited in PubMed and archived on PubMed Central

- yours - you keep the copyright

Submit your manuscript here:

http://www.biomedcentral.com/info/publishing_adv.asp
BioMedcentral 